\title{
New Scleral Fixation Technique for Subluxated Posterior Chamber İntraocular Lens
}

\author{
(D) Ugur Unsal, ${ }^{1}$ (D) Berkay Akmaz² \\ ${ }^{1}$ Department of Ophtalmology, Batigoz Eye Health Center, Izmir, Turkey \\ ${ }^{2}$ Department of Ophtalmology, Manisa City Hospital, Manisa, Turkey
}

\begin{abstract}
Objectives: This study describes a new scleral fixation technique to treat a subluxated intraocular lens (IOL). Methods: Four eyes of 4 patients were treated for a subluxated IOL with the described technique at Batigoz Eye Hospital. Demographic data, IOL type, and follow-up details were recorded, including the length of follow-up, postoperative refraction error, and complications.

Results: The study included 2 female and 2 male patients. The median age was 54 years (range: $45-66$ years). The mean duration of follow-up was 8 months (range: 5-13 months). Two of the subluxated IOLs were a monoblock subluxation of the IOL and the capsular tension ring, 2 were a 3-piece IOL. Follow-up examinations revealed no astigmatism $>$ I.50 D. An anterior vitrectomy was performed in I patient who had preoperatively prolapsed vitreous in the anterior chamber. No complication was observed throughout the follow-up.

Conclusion: This new scleral fixation technique facilitates fixation of a dislocated IOL. Compared with previous methods, this technique provides fixation of the subluxated IOL to the sclera with a less invasive procedure and less intraocular manipulation.
\end{abstract}

Keywords: Scleral fixation technique, subluxated intraocular lens, sutured scleral fixation.

\section{Introduction}

Intraocular lens (IOL) subluxation and dislocation are serious complications frequently seen during and after cataract surgery, and management can be difficult. An in-the-bag (in the capsule) or out-of-the-bag (extracapsular) IOL subluxation most often occurs in the late postoperative period $(1,2)$. The general increase in mean life expectancy has led to a corresponding increase in the number of cataract surgeries; therefore, it is clear that surgeons will encounter more of these cases. Subluxation can occur as a result of insufficient capsulo-zonular support $(1,3)$. The major predisposing factors for IOL subluxation include pseudoexfoliation (39.6\%), eye rubbing (14.8\%), long axial length (11.3\%), and a history of vitreoretinal surgery ( $10.4 \%)$. Other possible risk factors are intraoperative complications at the time of cataract surgery, atopic dermatitis, and retinitis pigmentosa. The risk varies according to the type of subluxation, i.e., in- or outof-the-bag subluxation. For instance, the leading risk factor is pseudoexfoliation for an in-the-bag dislocation, whereas it is capsular complication at the time of cataract surgery for an out-of-the-bag subluxation (4). 6(I): 62-65.

Address for correspondence: Berkay Akmaz, MD. Manisa Sehir Hastanesi, Oftalmoloji Klinigi, Manisa Turkey Phone: +90 5069171137 E-mail: berkayakmaz@hotmail.com

Submitted Date: July 16, 2020 Accepted Date: February 08, 2021 Available Online Date: February 12, 2021

${ }^{\circ}$ Copyright 2021 by Beyoglu Eye Training and Research Hospital - Available online at www.beyoglueye.com OPEN ACCESS This work is licensed under a Creative Commons Attribution-NonCommercial 4.0 International License. 
Management techniques for subluxated IOLs can be separated into I) removal of the subluxated IOL and secondary IOL implantation (anterior chamber implantation, iris fixation, or scleral fixation IOL), and 2) repositioning the subluxated IOL (scleral or iris fixation). Due to a larger corneal surgical incision, removal of the subluxated IOL can lead to a high rate of astigmatism and a greater need for a vitrectomy $(5,6)$.

Sutured and non-sutured fixation techniques continue to be widely used to treat a subluxated IOL. Scleral fixation of the IOL is preferred, as there is less damage to the anterior segment structures, glaucoma, cystoid macular edema, uveitis-glaucoma-hyphema syndrome, pigment dispersion, and pupil irregularity; it offers the opportunity for implantation where the IOL needs to be; and it reduces the incidence of anisocoria and optic deviations (7-9).

The presently described technique provides centralization and stabilization of the subluxated IOL with minimal intraocular manipulation and no requirement for special surgical instruments.

\section{Methods}

All of the operations were performed by the same surgeon (U.U.). Subtenon anesthesia was applied. The anterior chamber was accessed with a corneal sideport incision with a 20-G microvitreoretinal knife from the point where the fixation was to be applied and at the side $180^{\circ}$ opposite. The anterior chamber was filled with dispersive viscoelastic. A limbal conjunctival peritomy was performed and the sclera was cauterized. A 10-0 looped polypropylene suture (PC-9; Alcon Management S. A., Geneva, Switzerland) was introduced from the corneal sideport incision at the fixation point and passed from the anterior surface of the iris under the capsular tension ring (CTR) or haptic, and removed with a cannula that had been inserted into the anterior chamber from the opposite corneal sideport incision. At $2 \mathrm{~mm}$ from the limbus at the point where fixation was to be made, an insulin needle ( $26-\mathrm{G}, 0.45 \times 13 \mathrm{~mm}$ ), with the metal tip bent, was vertically introduced into the sclera.

The insulin needle in the anterior chamber was passed through the loop (Fig. I). Then the PC-9 suture and needle were re-entered from the opposite corneal sideport incision, and by placing the tip of the insulin needle over the CTR or lens haptic, it was removed from the sclera with the insulin needle. By passing the PC-9 needle through the loop, a suture that was locked to the CTR or the lens haptic was formed (Fig. 2). If looseness in the opposite side zonules was suspected, the same procedure was repeated on the opposite side. The sutures were knotted and fixed to the sclera, providing IOL centralization. The suture ends were cut and embedded in the sclera (Baykara, 2004). The viscoelastic was removed from anterior chamber with an irrigation aspiration cannula. The conjunctiva was closed with 8.0 Vicryl suture (Ethicon, Inc., Somerville, NJ, USA). All of the corneal incisions were sealed with corneal stromal hydration and were checked for leakage with a microsponge. A vitrectomy was not routinely performed, but an anterior vitrectomy from the limbus was performed in cases with vitreous prolapse. All of the patients were treated with topical moxifloxacin for I week and topical dexamethasone for 3 weeks.

Written, informed consent was provided by all of the study participants.

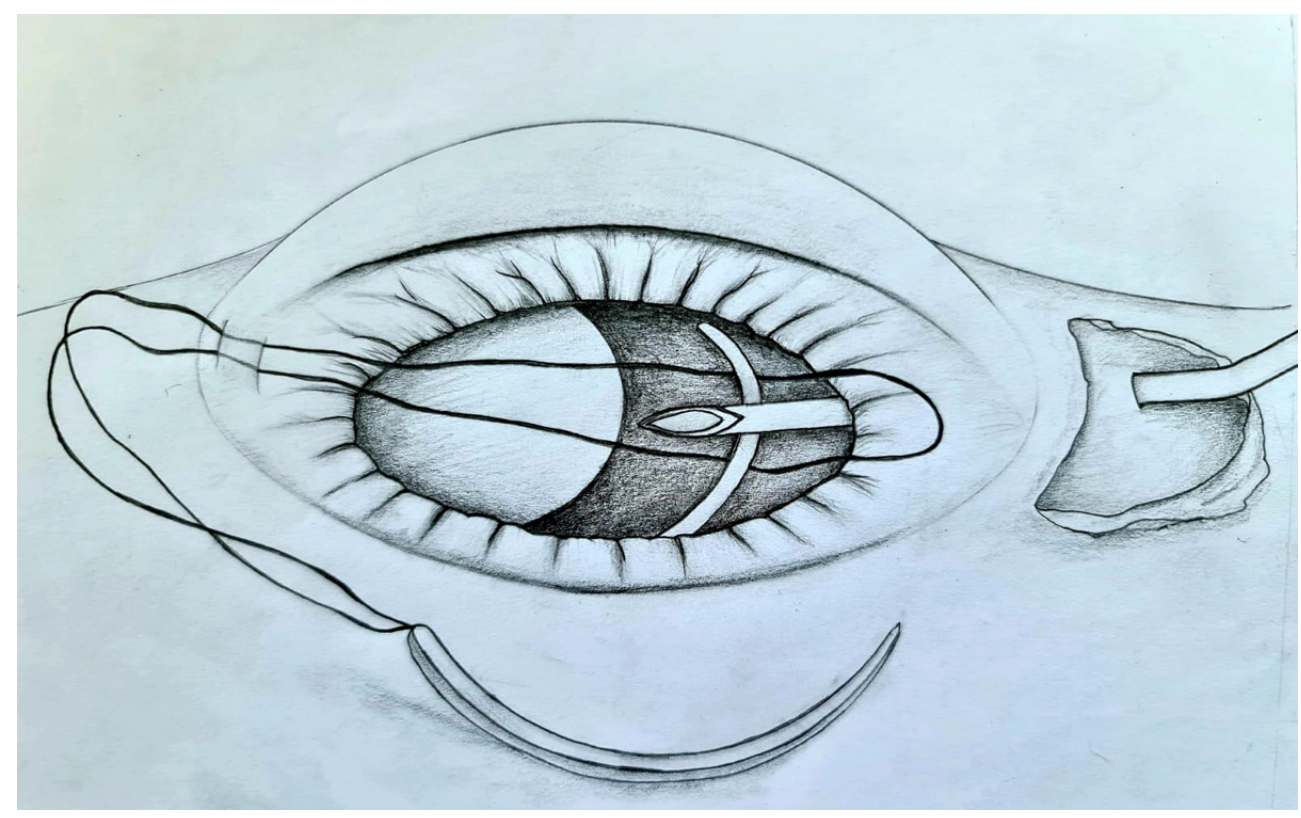

Figure I. The insulin needle is passed through the loop in the anterior chamber. 


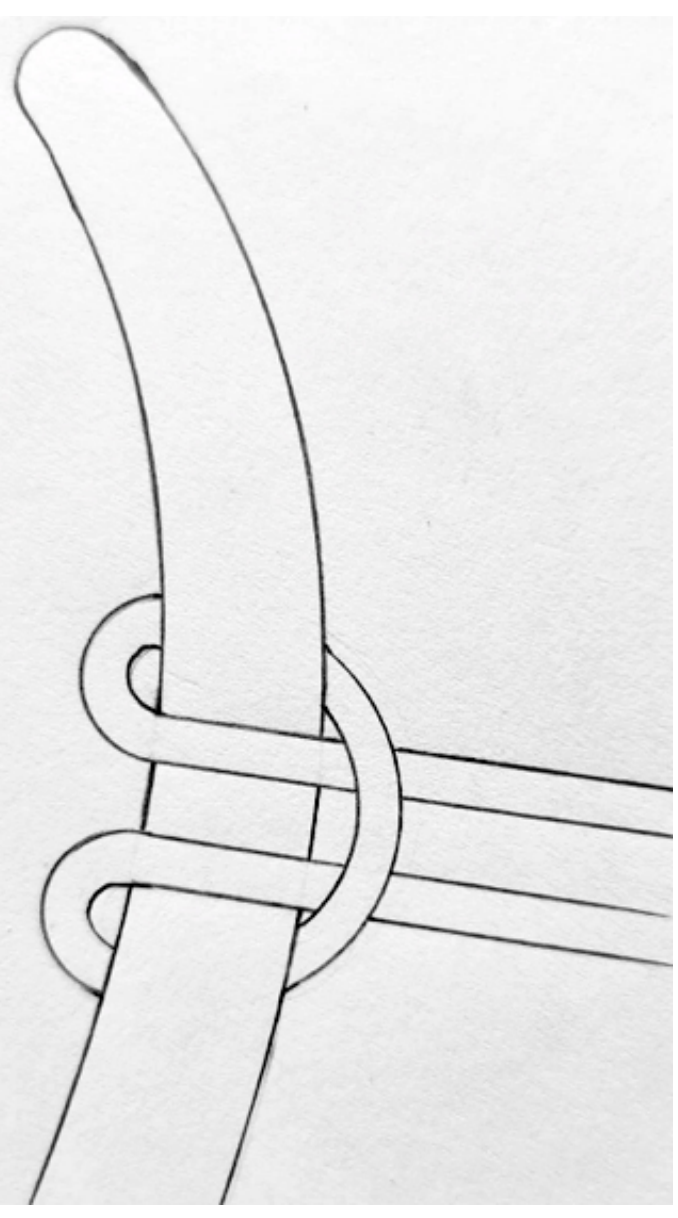

Figure 2. The knot is locked to the capsular tension ring or the haptic.

\section{Results}

This study included 4 eyes of 4 patients who were operated on at Batıgöz Hospital between January and April 2019. The patients were treated with repositioning using a scleral fixation technique due to a subluxated IOL. Two patients $(50 \%)$ were female, and $2(50 \%)$ were male. The median age of the patients was 54 years (range: 45-66 years).

The mean duration of follow-up of the patients was 8 months (range: $5-13$ months). All of the cases had a subluxated IOL-capsular bag complex: 2 were a monoblock subluxated IOL and CTR and 2 were a 3-piece IOL.

In the postoperative follow-up examinations, no astigmatism >I.50 D was observed. An anterior vitrectomy was performed in I case of prolapsed vitreous in the anterior chamber. No instance of cystoid macular edema, endophthalmia, anterior chamber reaction, choroid detachment, IOL tilt, or decentralization was observed. There was no need for re-operation in any patient throughout the follow-up period.

\section{Discussion}

Many techniques for fixation of an IOL to the sclera with sutures have been described. These can be separated into 2 categories: techniques applied by forming a loop around the haptic with intraocular manipulations (I0-2I) and techniques that use a knot created outside the eye from the sclerotomy of the haptic (22) or from the corneal incision $(23,24)$.

When the haptic is taken outside the eye, the suturing procedure is difficult. In addition, removing and replacing a haptic increases the number of manipulations, which creates a potential risk of damage to the peripheral retinal structures, iridodialysis, iris hemorrhage, or corneal endothelial damage. In the technique described in this paper, there is no need to take the haptic out of the eye.

In techniques where sclera fixation is made by forming a loop around the IOL haptic with intraocular maneuvers, it is necessary to form this loop and fix it to the sclera, and to use sclerotomies (10, I I,25-28) parasynthesis (12-14), microsurgery forceps (16) and/or perforated needles (15).

The previously defined intraocular cow-hitch knot technique requires bringing the subluxated lens to the anterior chamber and performing a $180^{\circ}$ rotation of the whole lens after making the loop (2I). These manipulations are thought to cause shrinkage in the vitreous, which could lead to retinal detachment. The technique described in this paper does not require removal of the dislocated lens to the anterior chamber or lens rotation. Each sclerotomy entry increases the risk of intraventricular hemorrhage, which is associated with choroid detachment, retinal detachment, and ciliary body vascular arch damage.

The presently described technique requires only 2 paracenteses and I sclerotomy in a unilateral scleral fixation case. Moreover, there is no need for the use of any special instruments, such as microsurgery forceps. This surgical technique can be applied safely and effectively in monoblock and 3-piece IOLs.

\section{Conclusion}

This is a successful and minimally invasive technique that can be applied simply, reliably, quickly, and inexpensively in the long-term treatment of a subluxated posterior chamber IOL.

\section{Disclosures}

Peer-review: Externally peer-reviewed.

Conflict of Interest: None declared.

Authorship Contributions: Involved in design and conduct of the study (UU, BA); preparation and review of the study ( $U U$, $B A)$; data collection (UU, BA); and statistical analysis (BA).

\section{References}

I. Hayashi K, Hirata A, Hayashi H. Possible Predisposing Factors for in-the-bag and out-of-the-bag intraocular lens dislocation and outcomes of intraocular lens exchange surgery. Ophthalmology 2007; | 14:969-75. [CrossRef]

2. Krèpšte L, Kuzmienè L, Miliauskas A, Janulevičienè I. Possible 
predisposing factors for late intraocular lens dislocation after routine cataract surgery. Medicina 2013;49:37. [CrossRef]

3. Ascaso FJ, Huerva V, Grzybowski A. Epidemiology, etiology, and prevention of late IOL-capsular bag complex dislocation: Review of the literature. J Ophthalmol 20I5;20I5:805706. [CrossRef]

4. Hayashi K, Ogawa S, Manabe S, Hirata A, Yoshimura K. A classification system of intraocular lens dislocation sites under operating microscopy, and the surgical techniques and outcomes of exchange surgery. Graefes Arch Clin Exp Ophthalmol 2016;254:505-13. [CrossRef]

5. Kristianslund $O$, Råen $M, \oslash$ stern $A E$, Drolsum L. Late in-thebag intraocular lens dislocation: A randomized clinical trial comparing lens repositioning and lens exchange. Ophthalmology 2017;124:151-9. [CrossRef]

6. Eum SJ, Kim MJ, Kim HK. A comparison of clinical outcomes of dislocated intraocular lens fixation between in situ refix-ation and conventional exchange technique combined with vitrectomy. J Ophthalmol 2016;2016:5942687. [CrossRef]

7. Biro Z. Results and complications of secondary intraocular lens implantation. J Cataract Refract Surg 1993; 19:64-7. [CrossRef]

8. Evereklioglu C, Er H, Bekir NA, Borazan M, Zorlu F. Comparison of secondary implantation of flexible open-loop anterior chamber and scleral-fixated posterior chamber intraocular lenses. J Cataract Refract Surg 2003;29:30I-8. [CrossRef]

9. Hannush SB. Sutured posterior chamber intraocular lenses: indications and procedure. Curr Opin Ophthalmol 2000; I I:23340. [CrossRef]

10. Bloom SM, Wyszynski RE, Brucker AJ. Scleral fixation suture for dislocated posterior chamber intraocular lens. Ophthalmic Surg 1990;2I:85I-4.

II. Campo RV, Chung KD, Oyakawa RT. Pars plana vitrectomy in the management of dislocated posterior chamber lenses. Am J Ophthalmol 1989;108:529-34. [CrossRef]

12. Azar DT, Wiley WF. Double-knot transscleral suture fixation technique for displaced intraocular lenses. Am J Ophthalmol 1999; I 28:644-6. [CrossRef]

13. Koh HJ, Kim CY, Lim SJ, Kwon OW. Scleral fixation technique using 2 corneal tunnels for a dislocated intraocular lens. J Cataract Refract Surg 2000;26: I439-4I. [CrossRef]

14. Kwok AK, Cheng AC, Lam DS. Surgical technique for transcleral-fixation of a dislocated posterior chamber intraocular lens. Am J Ophthalmol 200 I; 132:406-8. [CrossRef]

15. Smiddy WE. Modification of scleral suture fixation technique for dislocated posterior chamber intraocular lens implants. Arch Ophthalmol 1998; I 16:967.
16. Maguire AM, Blumenkranz MS, Ward TG, Winkelman JZ. Scleral loop fixation for posteriorly dislocated intraocular lenses. Operative technique and long-term results. Arch Ophthalmol 1991;109: 1754-8. [CrossRef]

17. Lawrence FC, 2nd, Hubbard WA. "Lens lasso" repositioning of dislocated posterior chamber intraocular lenses. Retina 1994; |4:47-50. [CrossRef]

18. Navia-Aray EA. A technique for knotting a suture around the loops of a dislocated intraocular lens, within the eye, for fixation in the ciliary sulcus. Ophthalmic Surg 1993;24:702-7.

19. Lee SC, Tseng SH, Cheng HC, Chen FK. Slipknot for scleral fixa- tion of intraocular lenses. J Cataract Refract Surg 200I;27:662-4. [CrossRef]

20. Virata SR, Holekamp NM, Meredith TA. Luggage-tag suture fixation of partially dislocated intraocular lenses. Ophthalmic Surg Lasers 200I;32:346-8.

2I. Hanemoto T, Ideta H, Kawasaki T. Dislocated intraocular lens fixation using intraocular cowhitch knot. Am J Ophthalmol 200I;| $31: 265-7$. [CrossRef]

22. Chan CK. An improved technique for management of dislocated posterior chamber implants. Ophthalmology 1992;99:5I-7.

23. Kokame GT, Yamamoto I, Mandel H. Scleral fixation of dislocated posterior chamber intraocular lenses: Temporary haptic externalization through a clear corneal incision. J Cataract Refract Surg 2004;30: 1049-56. [CrossRef]

24. Thach AB, Dugel PU, Sipperley JO, Sneed SR, Hollifield RD, Park DW, et al. Outcome of sulcus fixation of dislocated posterior chamber intraocular lenses using temporary externalization of the haptics. Ophthalmology 2000;107:480-4; discussion 5. [CrossRef]

25. Chan CC, Crandall AS, Ahmed IIK. Ab externo scleral suture loop fixation for posterior chamber intraocular lens decentra-tion: Clinical results. J Cataract Re-fract Surg 2006;32:I2I8. [CrossRef]

26. Chung EJ, Kim CY, Koh HJ. Ab externo direct suture technique for dislocated intraocular lens. J Cataract Re-fract Surg 2007;33:955-8. [CrossRef]

27. Gimbel HV, Brucks M, Dardzhikova AA, Camoriano GD. Scleral fixation of a subluxated intraocular lens-capsular bag complex through a fibrotic continuous curvilinear capsulorhexis. J Cataract Re-fract Surg 201 I;37:629-32. [CrossRef]

28. Han Q-H, Wang L, Hui Y-N. Transscleral suture technique for fixation of a dislocated posterior chamber intraocular lens. J Cataract Re-fract Surg 2004;30:1396-400. [CrossRef] 